\title{
SOLOS, MANEJO E ASPECTOS HIDROLÓGICOS NA BACIA HIDROGRÁFICA DO ARAÚJOS, VIÇOSA - MG ${ }^{1}$
}

\author{
Marcos Antonio Gomes², João Luiz Lani ${ }^{3}$, Liovando Marciano da Costa ${ }^{4}$, Lucas Machado Pontes ${ }^{5}$, Natália \\ Aragão de Figueredo ${ }^{6}$ e Nilson Gomes Bardales ${ }^{7}$
}

\begin{abstract}
RESUMO - Ao comparar dados passados com os atuais a respeito da vazão no ribeirão São Bartolomeu, Viçosa-MG, percebe-se uma desregularização nas últimas décadas. O objetivo deste trabalho foi estudar a influência das características físicas dos solos (Latossolo Vermelho-Amarelo - LVA e Argissolo Vermelho - PV) sob pastagem e a implantação de práticas de manejo e conservação de solo e água no comportamento hidrológico em uma microbacia do ribeirão São Bartolomeu. Na microbacia foi realizado o monitoramento da precipitação, vazão do curso d'água e nível de água dos lençóis freáticos antes e após a implantação de técnicas de manejo e conservação. O teor de argila dos solos foi maior no LVA em comparação ao PV, não indicando correlação com os resultados de densidade e porosidade do solo, mas influenciando na retenção de água no solo e na condutividade hidráulica, onde, no LVA a retenção de água foi maior do que no PV. A variação do lençol freático foi mais sensível na área do PV, resultado associado às características físicas deste solo e às técnicas de manejo implantadas. Como resultado a vazão mínima de 2004 foi de 188 L min-1, que em comparação com a vazão mínima de 2002 de 80 L min-1, indica um acréscimo de 108 L min-1 (135\%) o que confirma uma tendência da ação positivas das técnicas de conservação no abastecimento do lençol freático associado a importância de se conhecer as características do solo, o uso a que está sendo submetido e sua relação com o ciclo hidrológico.
\end{abstract}

Palavras-chave: Manejo de bacias hidrográficas, Revitalização de nascentes e Conservação de solo e água.

\section{SOILS, MANAGEMENT AND HYDROLOGICAL ASPECTS IN ARAÚJOS HYDROGRAPHIC BASIN, VIÇOSA - MG}

\begin{abstract}
When comparing the past and the current data referring to flow rate in São Bartolomeu creek, Viçosa - MG, it was found that some deregulation has occured in the last decades. The objective of this work was to study the influence of physical characteristics of two types of soils (Yellow-Red Latosol - LVA and Red Argisol - PV) under pasture as well as the implantation of some practices for both management and soil and water conservation in the hydrological behavior in São Bartolomeu creek microbasin. The monitoring of precipitation, flow rate of the water and the water level in the water tables were assessed before and after implantation of the management and conservation techniques. The soil clay contents were higher in LVA compared with PV, however indicating no correlation with the results for the soil density and porosity, but affecting both water retention into soil and the hydraulic conductivity, therefore the water retention in LVA was higher than PV. The water table variation was more sensitive in $P V$ as a result from the association of the physical characteristics of this soil and the management techniques applied. As a result, the minimum flow rate referring to 2004 was 188 L.min-1, which in comparison with the minimum flow rate of 80 L.min-1 referring to 2002 indicates an increment of 108 L.min-1 (135\%) which confirm a tendency of the of a positive action of the soil conservation techniques in provisioning the water depth associated to the importance of knowing the characteristics of the soil, the use which it has been submitted to and its relationship with the hydrological cycle.
\end{abstract}

Keywords: Management of hydrographic basins, Revitalization of the springs and Soil and water conservation.

${ }^{1}$ Recebido em 23.12.2010 e aceito para publicação em 15.11.2011.

22EPAMIG-UREZM - Empresa de Pesquisa Agropecuária de Minas Gerais. E-mail: <marcos.gomes@ufv.br>.

${ }^{3}$ Departamento de Solos, Universidade Federal de Viçosa, UFV, Brasil. E-mail: <lani@ufv.br>.

${ }^{4}$ Departamento de Solos, Universidade Federal de Viçosa, UFV, Brasil. E-mail: <liovando.costa@ufv.br>.

${ }^{5}$ Graduação em Engenharia Ambiental pela Universidade Feceral de Viçosa, UFV, Brasil. E-mail: <lucas.pontesm@gmail.com>.

${ }^{6}$ Programa de Pós graduação do Departamento de Solos, Universidade Federal de Viçosa, UFV, Brasil. E-mail: <nataliaragao@gmail.com>.

${ }^{7}$ Pesquisado do Governo do Estado do Acre. E-mail: <nilsonbard@yahoo.com.br>.

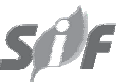

Revista Árvore, Viçosa-MG, v.36, n.1, p.93-102, 2012 


\section{INTRODUÇÃO}

Ao se comparar dados passados com os atuais a respeito da vazão de água em rios dos municípios da região de Viçosa - MG, percebe-se claramente a alteração da vazão nas últimas décadas. Inclui-se aí a bacia hidrográfica do ribeirão São Bartolomeu, principal manancial de abastecimento de água da cidade de Viçosa e da Universidade Federal de Viçosa - UFV. Registros históricos de vazão realizados pela UFV, indicam vazões no período de seca de $12.000 \mathrm{~L} \cdot \mathrm{min}^{-1}$ durante as década de 70 e 90, e de $6.000 \mathrm{~L} . \mathrm{min}^{-1}$ na atualidade.

Dentre os fatores responsáveis por esta queda de vazão apontam-se o desmatamento, o sobrepastejo e a descapitalização do agricultor para adotar práticas adequadas de manejo das pastagens, e mesmo de culturas agrícolas, nesta região de relevo acidentado. A atividade agrícola com ênfase na monocultura tem sido fator de aceleração da degradação do solo, geralmente ultimada pelo sobrepastejo e uso do fogo. Nesta fase inicia-se o processo de degradação da estrutura do solo e processos erosivos.

A erosão é uma das formas mais prejudiciais de degradação do solo, uma vez que reduz a capacidade produtiva das culturas, além de causar sérios danos ambientais, tais como, assoreamento e poluição das fontes de água (ZARTL et al., 2001; COGO et al., 2003).

Para Romkens et al. (2001), a erosão do solo é um fenômeno complexo, que envolve a desagregação e o transporte das partículas de solo, a infiltração da água no solo, o armazenamento de parte da água precipitada e o escoamento superficial. A magnitude relativa e a importância desses processos dependem de um conjunto de fatores, a saber: clima, solo, topografia, práticas de manejo do solo e cultura, práticas conservacionistas, condições antecedentes de umidade e tamanho da bacia hidrográfica.

O manejo a que o solo é submetido, pode tanto provocar sua degradação quanto seu melhoramento. No contexto de um manejo integrado e adequado de bacias hidrográficas com o intuito de reverter o quadro de redução de vazão dos mananciais e a depreciação da qualidade de suas águas, torna-se necessário conhecer o ciclo hidrológico regional, onde o solo assume uma posição de destaque, pois é o responsável pelo processamento da água.

Revista Árvore, Viçosa-MG, v.36, n.1, p.93-102, 2012
Neste sentido, o objetivo deste trabalho foi avaliar, na microbacia hidrográfica dos Araújos, as interações entre características morfológicas e físicas do solo e o comportamento hidrológico da bacia hidrográfica após aplicação de técnicas de manejo e conservação de solo e água.

\section{MATERIAL E MÉTODOS}

A pesquisa foi realizada na microbacia hidrográfica dos Araújos, com área de aproximadamente 51,3 ha (acima da estação registradora de vazão). Localiza-se entre coordenadas geográficas S $20^{\circ} 47^{\prime} 19,8^{\prime \prime}$ e WO $42^{\circ} 51^{\prime}$ 58,8', sendo um dos afluentes do córrego da Mata do Paraíso que deságua no ribeirão São Bartolomeu, o principal manancial de abastecimento da cidade de Viçosa - MG. A microbacia hidrográfica dos Araújos foi selecionada por representar as características das bacias hidrográficas do ribeirão São Bartolomeu em termos de solo, cobertura vegetal, uso do solo e características fisiográficas, conforme descrito por Santos (2007).

Foram descritos, conforme Santos et al., 2005, três perfis de solos e classificados de acordo com o Sistema Brasileiro de Classificação de Solos (EMBRAPA, 2006). O material coletado foi submetido às análises físicas (EMBRAPA, 1997): granulométrica, densidade do solo (Ds), densidade de partículas (Dp), argila dispersa em água, retenção de água no solo e condutividade hidráulica em meio saturado. Em complemento foram determinadas a microporosidade, porosidade total e macroporosidade.

Para início da pesquisa, no período de estiagem do ano de 2002, foram instalados na microbacia sistemas de monitoramento de vazão do curso de água e precipitação pluviométrica.

Os registros das informações de precipitação e vazão foram realizados até o período de estiagem do ano de 2009, entretanto as análises do comportamento hidrológico da bacia entre os anos de 2002 e 2005 foram suficientes para conclusão do estudo.

A precipitação foi monitorada por meio de um pluviógrafo de carta do tipo PLG - 007 e por quatro pluviômetros. O pluviógrafo foi instalado na parte central da microbacia hidrográfica e os pluviômetros distribuídos dentro da microbacia, para caracterizar da melhor forma possível a precipitação pluviométrica. 
Para o registro de vazão foi construído no curso d’água um vertedor triangular (0,5 m de altura, ângulo de $90^{\circ}$ no vértice e $1 \mathrm{~m}$ de largura na base) conjugado a um vertedor retangular (0,5 m de altura e $1 \mathrm{~m}$ de largura), o local de instalação permitiu o monitoramento da vazão numa área de aproximadamente 51,3 ha. Junto ao vertedor foi instalado um linígrafo (Thalimedes) com sistema computadorizado "data logger" para registro das alturas linimétricas, posteriormente transformadas em vazão pela equação 1 e 2 (DAKER, 1983), respectivamente, para alturas de 0 a $50 \mathrm{~cm}$ que corresponde a parte triangular do vertedor e para alturas de 50 a $100 \mathrm{~cm}$ correspondente à parte retangular do vertedor:

$$
\begin{array}{ll}
Q=1,4 \times H^{2,5} & (\text { Equação 1) } \\
Q=1,77 \times L \times H^{1,5} & \text { (Equação 2) }
\end{array}
$$

em que, $\mathrm{Q}=$ vazão em $\mathrm{m}^{3} \cdot \mathrm{s}^{-1} ; \mathrm{H}=$ altura da lamina d’água em m; e L = largura da soleira em $\mathrm{m}$.

Em complemento à pesquisa foi realizado o monitoramento do nível de água dos lençóis freáticos das nascentes localizadas nas áreas de LVA e PV. Os poços foram perfurados até atingir a camada impermeável e posteriormente revestido com cano de PVC ( $Æ=100$ $\mathrm{mm}$ ) e as leituras do nível de água realizadas diariamente em horário pré estabelecido (9:00 am).

Após a instalação dos sistemas de monitoramento e identificação das classes de solo, foram implantadas técnicas de conservação de solo e água em algumas áreas da bacia hidrográfica.

Para a retenção da água de escoamento superficial laminar nas áreas de pastagem, foram implantados os terraços ou curva de nível com distância padrão de 12 metros entre terraços, independente da declividade ou classe de solo. Para a retenção das águas de escoamento superficial concentradas, ou enxurradas, formadas ao longo das erosões nas áreas de pastagem e as margens das estradas foram construídas as caixas de captação de água. Buscou-se priorizar a meia encosta e o terço superior das encostas para a implantação das técnicas de conservação e reflorestamentos, conforme Pinto (2005).

\section{RESULTADOS}

\subsection{Solos}

Foram identificadas três principais classes de solos na área (51,3 ha) da microbacia dos Araújos.
Porém, o desenvolvimento deste trabalho foi realizado com foco em duas classes de solos: Latossolo Vermelho-Amarelo Distrófico A moderado, ocupando 37,3 ha, apresentando textura muito argilosa, fase floresta tropical sub-perenifólia e relevo forte ondulado - possui pedoforma convexa-convexo característica e em concordância com Corrêa (1984), tanto no Planalto de Viçosa como no domínio dos “Mares de Morros” na Zona da Mata Mineira. A pedoforma convexa-convexo indica uma forma que tende a reter o mínimo de água, favorecendo a enxurrada e a erosão (RESENDE et al., 1992), predominantemente laminar; e, ocupando 11 ha, o solo Argissolo Vermelho Tb Distrófico A moderado textura argilosa fase floresta tropical sub-perenifólia relevo forte ondulado e ondulado com inclusão e afloramento de rocha - Pedoforma de ocorrência do tipo côncava-côncavo, essa formação se caracteriza pela tendência a reter a água e possuir maior instabilidade nas partes mais altas e maior estabilidade nas áreas mais baixas.

\subsection{Análise granulométrica, densidade e porosidade do solo}

O resultado da análise do solo (Tabela 1) indica no LVA a classe textural argilosa até a profundidade de $55 \mathrm{~cm}$ e muito argilosa entre 55 e $100 \mathrm{~cm}$. No PV a variação foi de argilo arenosa - argilosa - muito argilosa. O gradiente textural e a cerosidade observada, ainda que fraca e moderada, confirmam a formação do Bt. No Argissolo Vermelho ocorreu os maiores valores de densidade do solo e os menores valores de macroporosidade.

\subsection{Curvas de retenção de água e condutividade hidráulica}

As análises de retenção de água no solo (Figura 1) foram realizadas nas tensões de -6 e $-10 \mathrm{kPa}$, por serem esses os valores relacionados à capacidade de campo, ou seja, momento em que o solo se apresenta saturado e participa ativamente do processo de infiltração e percolação. A variabilidade da retenção de água no solo está diretamente associada à velocidade de infiltração e percolação da água ao longo do seu perfil, contribuindo para maior ou menor taxa de escoamento superficial e recarga do lençol freático.

A condutividade hidráulica (Tabela 1) na profundidade de $0-10 \mathrm{~cm}$ no LVA apresentou valor de $115,45 \mathrm{~cm} \mathrm{~h}^{-1}$, contrastando com a condutividade

Revista Árvore, Viçosa-MG, v.36, n.1, p.93-102, 2012 
Tabela 1 - Características físicas do LVA e PV na microbacia hidrográfica dos Araújos, Viçosa, MG.

Table 1 - Physical characteristics of the LVA and PV in the microbasin of the Araújos creek, Viçosa, MG.

\begin{tabular}{|c|c|c|c|c|c|c|c|c|c|c|}
\hline \multirow{3}{*}{$\begin{array}{c}\text { Prof. } \\
\text { cm }\end{array}$} & \multicolumn{2}{|c|}{ Areia } & \multirow[t]{2}{*}{ Silte } & \multirow[t]{2}{*}{ Arg. } & \multicolumn{2}{|c|}{ Densidade } & \multicolumn{3}{|c|}{ Porosidade } & \multirow{3}{*}{$\begin{array}{c}\mathrm{CH} \\
\mathrm{cm} \mathrm{h}^{-1} \\
\end{array}$} \\
\hline & Gr & $\mathrm{F}$ & & & Solo & Part. & Micro & Macro & Total & \\
\hline & \multicolumn{4}{|c|}{$-\cdots \cdots \mathrm{g} \mathrm{kg}^{-1} \cdots \cdots$} & \multicolumn{2}{|c|}{$-\mathrm{kg} \mathrm{dm}^{-3}-$} & \multicolumn{3}{|c|}{$\ldots-\cdots \mathrm{m}^{3} \mathrm{~m}^{-3} \cdots--$} & \\
\hline \multicolumn{11}{|c|}{ Argissolo Vermelho } \\
\hline $0-5$ & 370 & 90 & 110 & 430 & 1,36 & 2,65 & 0,39 & 0,10 & 0,49 & - \\
\hline $5-10$ & 320 & 100 & 130 & 450 & - & - & - & - & - & 22,00 \\
\hline $10-15$ & 370 & 90 & 130 & 410 & 1,42 & 2,71 & 0,33 & 0,15 & 0,48 & - \\
\hline $15-25$ & 350 & 90 & 120 & 440 & - & - & - & - & - & 21,74 \\
\hline $25-35$ & 280 & 90 & 110 & 520 & - & - & - & - & - & - \\
\hline $35-55$ & 210 & 60 & 90 & 640 & 1,44 & 2,80 & 0,44 & 0,05 & 0,48 & 21,70 \\
\hline $55-75$ & 200 & 50 & 80 & 670 & - & - & - & - & - & \\
\hline $75-100$ & 190 & 60 & 70 & 680 & 1,33 & 2,81 & 0,43 & 0,10 & 0,53 & 10,02 \\
\hline \multicolumn{11}{|c|}{ Latossolo Vermelho Amarelo } \\
\hline $0-5$ & 290 & 110 & 130 & 470 & 1,20 & 2,71 & 0,40 & 0,16 & 0,56 & - \\
\hline $5-10$ & 240 & 120 & 150 & 490 & - & - & - & - & - & 115,45 \\
\hline $10-15$ & 240 & 100 & 150 & 510 & 1,22 & 2,80 & 0,39 & 0,17 & 0,56 & - \\
\hline $15-25$ & 220 & 110 & 130 & 540 & - & - & - & - & - & 10,16 \\
\hline $25-35$ & 210 & 110 & 130 & 550 & - & - & - & - & - & - \\
\hline $35-55$ & 210 & 90 & 130 & 570 & 1,22 & 2,93 & 0,31 & 0,27 & 0,58 & 9,61 \\
\hline $55-75$ & 140 & 80 & 100 & 680 & - & - & - & - & - & - \\
\hline $75-100$ & 140 & 80 & 110 & 670 & 1,14 & 2,85 & 0,44 & 0,16 & 0,60 & 10,02 \\
\hline
\end{tabular}

Gr - Grossa; F- Fina; Arg. - Argila; Part - Partícula; CH - Condutividade Hidráulica.

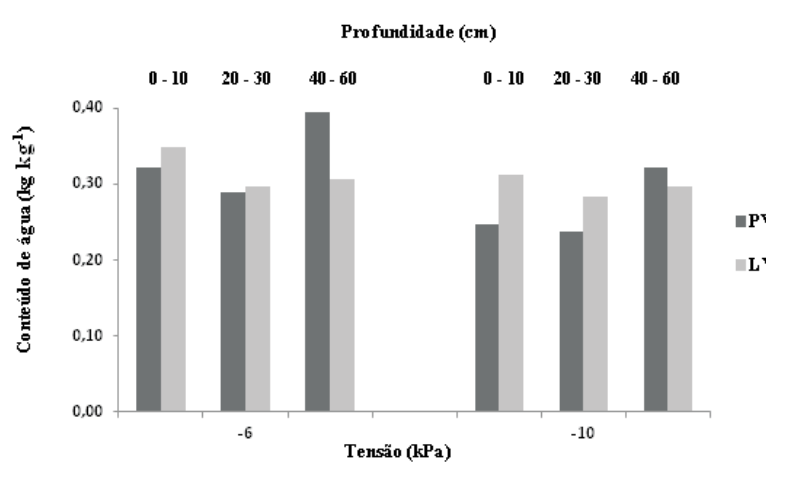

Figura 1 - Retenção de água nos solos PV e LVA na microbacia. Figure 1 - Water retention in LVA and PV soils in the microbasin.

de $22 \mathrm{~cm} \mathrm{~h}^{-1}$ do PV. Nas profundidades de $20-30 \mathrm{~cm}$ e $35-55 \mathrm{~cm}$ a condutividade no PV se mantém estável com valores da mesma ordem em relação à primeira profundidade, em contrapartida as condutividades nas duas profundidades no LVA diminui para valores em torno de $10 \mathrm{~cm} \mathrm{~h}^{-1}$. Na última profundidade analisada, $75-100 \mathrm{~cm}$, o valor de condutividade do PV diminui para $10 \mathrm{~cm} \mathrm{~h}^{-1}$ e apresenta condutividade semelhante ao do LVA.

Revista Árvore, Viçosa-MG, v.36, n.1, p.93-102, 2012

\subsection{Profundidade do lençol freático}

Ao se comparar a variação do nível lençol freático do poço 1 localizado na área de LVA com o do poço 2 localizado no PV, nota-se uma diversidade de comportamento durante todo o ano frente as precipitações (Figura 2).

\subsection{Vazão do curso d'água}

A oscilação da vazão do curso d' água que drena a microbacia dos Araújos, durante os meses de fevereiro a novembro de 2004, tende a acompanhar a oscilação dos níveis de água dos lençóis freáticos.

A retenção de água do escoamento superficial pelas técnicas de conservação de solo reflete em aumento da recarga do lençol freático e de forma direta nas vazões do manancial ao longo do ano.

As hidrógrafas (Figura 3) indicam os resultados positivos na diminuição do escoamento superficial na microbacia dos Araújos. No período de chuva, ao se comparar a hidrógrafa de vazão do manancial antes da implantação das técnicas de conservação, representada pela linha tracejada, com a hidrógrafa após os trabalhos é possível verificar a redução do pico de vazão no manancial, linha contínua. 


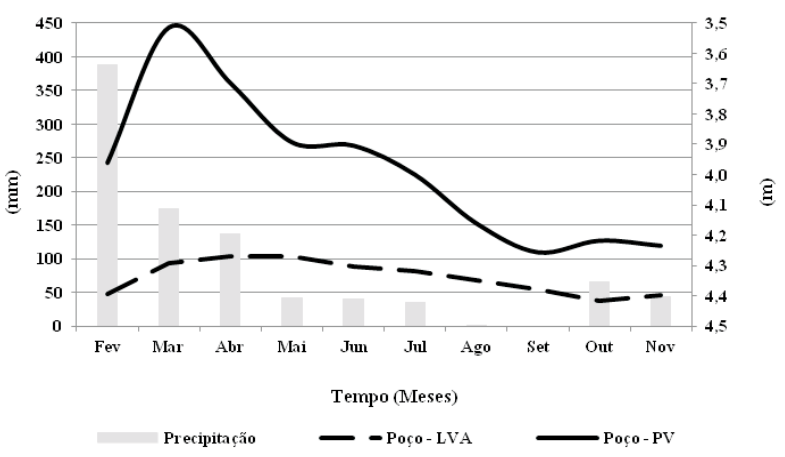

Figura 2 - Variação do nível do lençol freático em relação à precipitação pluviométrica.

Figure 2 - Variation of groundwater level in relation to rainfall.

A redução dos picos de vazão refletiu no aumento de vazão mínima (Figura 4), mensurada no período de estiagem pelo sistema contínuo de monitoramento.

\section{DISCUSSÃO}

\subsection{Solos}

O aumento da concentração de argila em profundidade, constatada nos solos, interfere na condutividade hidráulica e dificulta o processo de

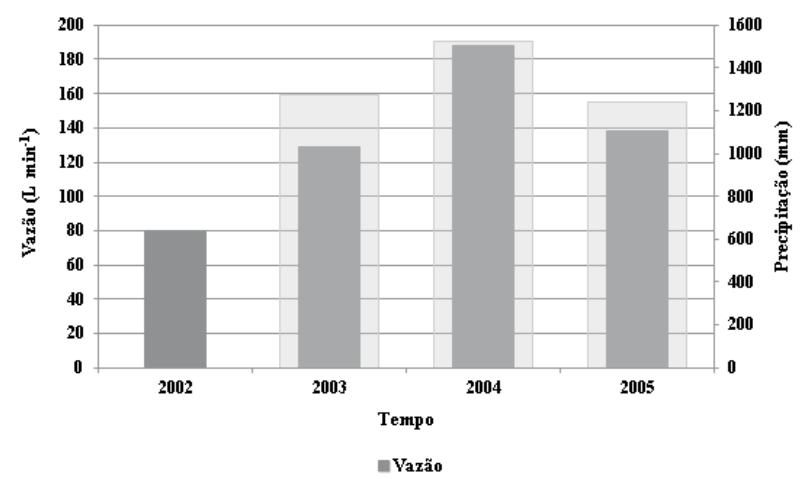

Figura 4 - Precipitação total e vazão mínima na microbacia dos Araújos após a implantação das técnicas de manejo e conservação de solo e água.

Figure 4-Total rainfall and minimum flow rate in the microbasin of Araujos creek after the implementation of conservation techniques.

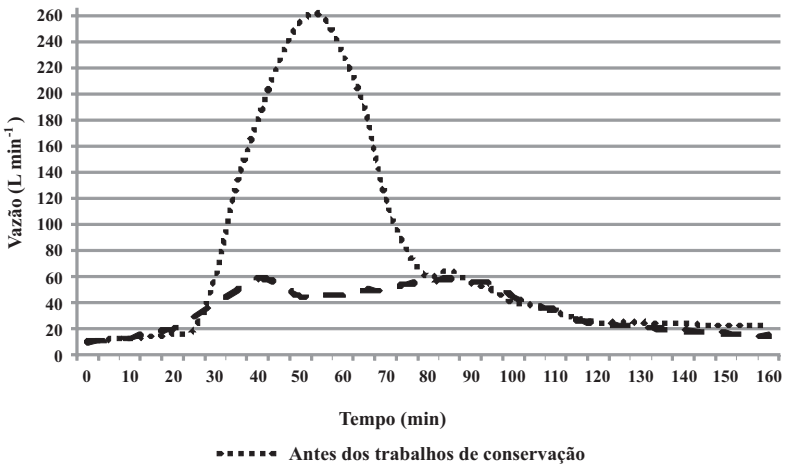

Figura 3 - Vazão do córrego dos Araújos antes e depois da implantação das técnicas de manejo e conservação.

Figure 3 - Flow rate of Araújos creek before and after the implementation of conservation techniques.

percolação da água que infiltra, podendo influenciar na formação de escoamento superficial e de processos erosivos.

Os resultados de Rawls et al. (1991) e Rawls et al. (2003) mostram que, em elevado potencial mátrico (ø), a curva de retenção é influenciada por poros estruturais associados ao efeito da matéria orgânica na formação e na estabilidade da estrutura do solo. Em baixo ø, a composição granulométrica e a mineralogia do solo tornam-se mais importantes devido à superfície disponível para a adsorção de água. Dessa forma, a curva de retenção de água está relacionada a diferentes propriedades do solo, como o teor de argila, o teor de C orgânico, a área superficial específica e a densidade do solo (VAN DEN BERG et al., 1997).

\subsection{Análise granulométrica}

A granulometria se apresenta como uma informação útil, na definição de classes taxonômicas, na atuação de processos pedogenéticos, além de favorecer o entendimento do movimento de água no corpo do solo, o manejo da adubação, assim como o estabelecimento de práticas conservacionistas e planejamento ambiental (MULLA; MCBRATNEY, 2002).

\subsection{Densidade e porosidade do solo}

Os maiores valores de densidade do solo foram encontrados no Argissolo Vermelho (Tabela 1), o que indica uma maior massa de solo seco por unidade de volume, certamente por influência do horizonte Bt. 
Em comparação ao PV, os menores valores de densidade do LVA parecem estar relacionados à condição estrutural desse solo, uma vez que ambos os ambientes estão submetidos ao mesmo tipo de uso do solo. A maior densidade, comparado ao LVA, pode estar associado à compactação causada pelo pastoreio intensivo e pela diminuição de matéria orgânica. A maior densidade dos solos de uso agrícola está relacionada a vários fatores, dentre eles, com a compactação do solo pelo uso intensivo(HARTEMINK, 1998; CAVENAGE et al., 1999) e com a redução dos teores de matéria orgânica (SILVA e KAY, 1997; DALAL; CHAN, 2001).

O PV apresentou os menores valores de macroporosidade. Esses resultados expressam a interrelação entre a porosidade e a densidade do solo, ou seja, o aumento da densidade reflete uma redução da porosidade devido à diminuição de macroporos (ALVES, 2007). Beutler et al. (2002) e Machado et al. (2008), afirmam que o conteúdo de água retido em determinado potencial mátrico (ø) decorre da estrutura e da distribuição dos tamanhos de poros. O destacado papel do espaço poroso na dinâmica da água no solo foi reconhecido por vários pesquisadores, como Anderson e Bouma (1973) e Bortoluzzi et al. (2008) que ressaltam que para se entender melhor o comportamento do solo, a distribuição dos poros por seus tamanhos é mais importante que a porosidade total. A esse respeito, Klein (2002) afirma que, para diversos objetivos, tais como o movimento e armazenamento de água e gases, fluxo e retenção de calor e desenvolvimento do sistema radicular, a determinação somente da porosidade total fornece informações de importância limitada. Deste modo, a determinação da distribuição dos poros na matriz do solo apresenta-se mais importante, visto que, de acordo com a distribuição dos diferentes tamanhos dos poros, pode haver restrição do fluxo de água no solo.

Nessas condições de modificação da relação massa/ volume do solo, quer seja natural ou antropogênica, ocorre diminuição da entrada de água no perfil do solo e no comportamento da sua redistribuição e retenção, em virtude das alterações da porosidade do solo (SOTO, et al., 2007; ALVES et. al., 2007), o que influencia em alguns segmentos do ciclo hidrológico como, a capacidade de infiltração, percolação da água e escoamento superficial, E exigindo, portanto, maior atenção quanto ao uso e aplicação de técnicas de manejo e conservação de solo e água.

Revista Árvore, Viçosa-MG, v.36, n.1, p.93-102, 2012

\subsection{Curvas de retenção de água}

Nas tensões analisadas, as curvas de retenção de água não mostraram relações nítidas com a porosidade e densidade do solo, mas sim, com a fração argila e classe textural de cada solo. O PV, com os menores valores de macroporosidade, quantidades de argila e classe textural variando de argilo-arenosa a argilosa, apresentou os menores valores de retenção de água nas profundidades $0-10 \mathrm{~cm}$ e $20-30 \mathrm{~cm}$, situação contraria a última profundidade analisada onde o PV apresentou o maior valor de retenção de água.

A retenção de água no Latossolo Vermelho Amarelo apresentou valores pouco superiores em relação ao $\mathrm{PV}$, acompanhado dos valores de macroporosidade, quantidade de argila e classe textural argilosa.

Eltz et al. (1989) e Luz et al. (2008) verificaram o aumento da retenção de água em conformidade com o aumento dos teores de argila no solo. Cada solo possui uma curva característica ou de retenção de água, associado às propriedades físico-químicas da fração sólida e do arranjo poroso. A compactação do solo, perda e/ou adição de matéria orgânica, afetam a forma da curva e podem atuar na capacidade de água disponível do solo (ARAUJO et al., 2004).

Para altos conteúdos de água, nos quais fenômenos capilares são de importância na retenção de água, esta retenção depende da densidade do solo e da porosidade, enquanto, para menores conteúdos de água, em que o fenômeno de adsorção domina, a retenção de água depende mais da textura e da superfície específica do solo(HILLEL, 1970; BLEUTER etal., 2002; BORTOLUZZI et al., 2008).

\subsection{Condutividade hidráulica}

A diminuição na velocidade de infiltração para o LVA parece estar associada ao aumento da quantidade de argila ao longo do perfil do solo, passando da classe textural argilosa para muito argilosa.

A condutividade hidráulica não mostrou uma relação clara com a porosidade do solo, e sim, com o aumento no teor de argila, acompanhando a tendência dos resultados de retenção de água no solo. De acordo com Beltrán (1986), a condutividade hidráulica do solo saturado depende da fluidez da água, que é proporcional a sua viscosidade e densidade, e da macroporosidade 
do solo que, por sua vez, é função da textura e da estrutura. Back et al. (1990), Barreto, et al. (2001) e Mesquita, et al. (2004) afirmam que a condutividade hidráulica depende da textura, do arranjo das partículas (estrutura), da dispersão das partículas finas e da sua densidade.

As características do solo que modificam o valor de condutividade são porosidade, distribuição de tamanho de poros, tortuosidade dos interstícios e teor de argila (ALVES et al., 2007).

A livre passagem da água no solo é um fator determinante na redução do escoamento superficial e da erosão, com conseqüente aumento no abastecimento do lençol freático. Assim, nota-se a importância de conhecer as características físicas do solo antes da recomendação de qualquer técnica de manejo e conservação de água e solo.

\subsection{Profundidade do lençol freático}

O nível do lençol freático do poço 2 tem maior oscilação nos períodos de chuva e de seca quando comparado ao poço 1. Essa variação mais acentuada pode estar associada ao tipo de solo (Argissolo Vermelho) onde os resultados das suas características físicas como, menor capacidade de retenção de água nas tensões de -6 e -10 KPa e maior quantidade de areia nas primeiras camadas de solo caracterizando-o como argilo-arenosa contribuem para o aumento da infiltração e percolação, refletindo na diminuição do escoamento superficial.

A pedoforma côncava-côncavo da área de influência do poço 3 contribui para a retenção da água no local, situação contrária encontrada para a área de influência do poço 2 que apresenta formação convexa-convexo, formação que tende a acentuar o escoamento superficial e os processos erosivos (RESENDE et al., 2005).

A maior oscilação e recarga do lençol freático no PV não estão associadas somente às características físicas do solo ou de sua pedoforma, e sim, com maior importância, à implantação das técnicas de conservação de solo e água que retém a água de escoamento superficial quando a capacidade de infiltração da água chega ao seu limite.

Os resultados encontrados mostram a sensibilidade do comportamento hidrológico de uma microbacia hidrográfica em diferentes classes de solos com o mesmo uso.
O lençol freático localizado na área do PV foi o que mostrou maior relação e sensibilidade junto à oscilação da vazão no curso d’água frente às precipitações ocorridas. Associa-se este fato às características físicas que melhoram as taxas de infiltração do PV e, principalmente, às técnicas de conservação de solo e água implantados na área de domínio desse solo.

As áreas acima da linha contínua nas hidrógrafas (Figura 3) representam o escoamento superficial após a ocorrência de precipitações pluviométricas com mesma intensidade e quantidade (45 $\mathrm{mm} \mathrm{h}^{-1} / 24 \mathrm{~mm}$ ) e a parte abaixo da linha contínua, o escoamento proveniente do lençol freático, denominado escoamento de base.

As hidrógrafas possuem formatos diferentes, representando o volume de água que passou pelo vertedor após a ocorrência da precipitação.

A hidrógrafa, representada pela linha tracejada, possui um formato mais achatado, indicando que houve uma redução no escoamento superficial que chegou a aproximadamente 55 \%, em comparação ao escoamento superficial representado pela outra hidrógrafa (linha pontilhada). Isso significa que água precipitada foi retida na bacia hidrográfica, mas não se pode afirmar que toda a água retida foi para o lençol freático devido às perdas pelo processo de evapotranspiração.

\subsection{Vazão do curso d’água}

Com precipitação pluviométrica de 1276,5 mm no período úmido de 2002 e 2003 a vazão mínima do manancial que era de $80 \mathrm{~L} \mathrm{~min}^{-1}$ aumentou para $129 \mathrm{~L} \mathrm{~min}^{-1}$, um acréscimo de $61 \%$ na vazão mínima do curso d’água. Entre os anos de 2003 e 2004, com precipitação total de 1523,5 mm, a vazão mínima de $129 \mathrm{~L} \mathrm{~min}^{-1}$ aumentou para $188 \mathrm{~L} \mathrm{~min}^{-1}$, um acréscimo de $46 \%$ que está relacionado ao aumento da precipitação total anual.

No ano de 2005 para uma precipitação de 1.240 mm a vazão foi de $138 \mathrm{~L} \mathrm{~min}^{-1}$, indicando uma estabilização da vazão mínima para as precipitações médias que ocorrem na região.

O aumento da vazão mínima para os referidos anos de monitoramento indicam os efeitos positivos das técnicas de conservação de solo e água na retenção do escoamento superficial, aumento da infiltração e recarga dos lençóis freáticos.

Revista Árvore, Viçosa-MG, v.36, n.1, p.93-102, 2012 


\section{CONCLUSÕES}

- A variação na velocidade de infiltração de água no solo está relacionada com a porosidade (macroporosidade) no PV e os teores de argila no LVA;

- Nas tensões analisadas, para os dois solos, as curvas de retenção de água estão relacionadas os teores de argila;

- A variação de nível do lençol freático apresentou comportamento diferente para as características físicas dos solos, o que indica a importância do comportamento do solo no abastecimento do lençol freático e a necessidade de sua prévia caracterização para o desenvolvimento de planos de manejo de bacias hidrográficas;

- A diminuição do escoamento superficial verificado nas hidrógrafas e o aumento na vazão mínima no manancial indicam a eficácia das técnicas de conservação de solo e água na retenção do escoamento superficial e abastecimento do lençol freático.

- Os resultados obtidos reforçam a importância de se conhecer as características do solo, o uso a que está sendo submetido e sua relação com o ciclo hidrológico. O conhecimento é essencial para a recuperação e conservação de nascentes com o uso das técnicas de manejo e conservação de solo e água.

\section{AGRADECIMENTO}

À FAPEMIG pelo financiamento da pesquisa e pela bolsa concedida.

\section{REFERENCIAS}

ALVES, M. C.; SUZUKI, L. G. A.; SUZUKI, L. E. A. S. Densidade do solo e infiltração de água como indicadores da qualidade física de um Latossolo Vermelho distrófico em recuperação. Revista Brasileira de Ciência do Solo, v.31, n.4, p.617-625, 2007.

ANDERSON, J. L.; BOUMA, J. Relationships between saturated hydraulic conductivity and morphometric data of an argillic horizon. Soil Science Society American Proceedings, v.37, n.3, p.408-413, 1973.

ARAUJO, M.A.; TORMENA, C. A.; SILVA, A. P. Propriedades físicas de um latossolo vermelho distrófico cultivado e sob mata nativa. Revista Brasileira de Ciência do Solo, v.28, n.2, p.337-345, 2004.
BACK, A. J. et al. Sistemas de drenagem em regime variável. Revista Ceres, v.37, n.209, p.36-49, 1990.

BARRETO, A. N. et al. Condutividade hidráulica saturada em um solo aluvial do perímetro irrigado de São Gonçalo, PB. Revista Brasileira de Engenharia Agricola e Ambiental, v.5, n.1, p.152-155, 2001.

BELTRÁN, J. M. Drenaje agricola. Madrid: Ministerio da Agricultura, Pesca y Alimentacion, 1986. 239p.

BLEUTER, A. N. et al. Retenção de água em dois tipos de Latossolos sob diferentes usos.

Revista Brasileira de Ciência do Solo, v.26, n.3, p.829-834, 2002.

BORTOLUZZI, E. C. et al. Porosidade e retenção de água em um argissolo sob manejos convencional e direto submetido a compressões unidimensionais. Revista Brasileira de Ciência do Solo, v.32, n.4, p.1447-1457, 2008.

CAVENAGE, A. et al. Alterações nas propriedades físicas de um Latossolo VermelhoEscuro sob diferentes culturas. Revista Brasileira de Ciência do Solo, v.23, n.4, p.997-1003, 1999.

CORRÊA, G. F. Modelo de evolução e mineralogia da fração argila dos solos do planalto de Viçosa, MG. 1984. 84f. Dissertação (Mestrado em Solos e Nutrição de Plantas) - Universidade Federal de Viçosa, Viçosa, MG, 1984.

COGO, N. P.; LEVIEN, R.; SCHWARZ, R. A. Perdas de solo e água por erosão hídrica influenciadas por métodos de preparo, classes de declive e níveis de fertilidade do solo. Revista Brasileira de Ciência do Solo, v.27, n.4, p.743-753, 2003.

DAKER, A. Captação, elevação e melhoramento da água. Rio de Janeiro: Freitas Bastos, 1983. 408p.

DALAL, R. C.; CHAN, K. Y. Soil organic matter in rainfed cropping systems of the Australian cereal belt. Australian Journal Soil Research, v.39, n.3, p.435-464, 2001. 
ELTZ, F. L. F.; PEIXOTO, R. T. G.; JASTER, F. Efeitos de sistemas de preparo do solo nas propriedades físicas e químicas de um Latossolo Bruno não álico. Revista Brasileira de Ciência do Solo, v.13, n.2, p.259-267, 1989.

\section{EMPRESA BRASILEIRA DE PESQUISA} AGROPECUÁRIA - EMBRAPA. Centro Nacional de Pesquisa de Solos. Manual de métodos de análises de solo. Rio de Janeiro: 1997. 212p.

EMPRESA BRASILEIRA DE PESQUISA AGROPECUÁRIA - EMBRAPA. Centro Nacional de Pesquisa de Solos. Sistema brasileiro de classificação de solos. Rio de Janeiro: 2006. 306p.

HARTEMINK, A. E. Soil chemical and physical properties as indicators of sustainable land management under sugar cane in Papua New Guinea. Geoderma, v.85, p.283-306, 1998.

HILLEL, D. Solo e água: Fenômenos e princípios físicos. Traduzido pelo convênio UFRGS-USAID/ Wisconsin. Porto Alegre: Universidade Federal do Rio Grande do Sul, 1970. 231p.

KLEIN, V. A.; LIBARDI, P. L. Condutividade hidráulica de um Latossolo Roxo, não saturado, sob diferentes sistemas de uso e manejo.

Ciência Rural, v.32, n.6. p.945-953, 2002.

LUZ, L. R. Q. P.; LIMA, S. L. Atributos físicos e hídricos de solos em toposseqüência de tabuleiros costeiros. Revista de Energia na Agricultura, v.23, n.1, p.44-59, 2008.

MACHADO, J. L. et al. Inter-relações entre as propriedades físicas e os coeficientes da curva de retenção de água de um latossolo sob diferentes sistemas de uso. Revista Brasileira de Ciência do Solo, v.32, n.2, p.495-502, 2008.

MESQUITA, M. G. B. F.; MORAES, S. O. A dependência entre a condutividade hidráulica saturada e atributos físicos do solo. Ciência Rural, v.34, n.3, p.963-969, 2004.

MULLA, D. J.; McBRATNEY, A. B. Soil spatial variability. In: WARRICK, A. W. (Ed.). Soil physics companion. Boca Raton: CRC Press, 2002. p.343-347.
PINTO, L. V. A. et al. Estudo da vegetação como subsídios para propostas de recuperação das nascentes da bacia hidrográfica do ribeirão Santa Cruz, Lavras, MG. Revista Árvore, v.29, n.5, p.775-793, 2005.

RAWLS, W. J.; GISH, T. J.; BRAKENSIEK, D. L. Estimating soil water retention from soil physical properties and characteristics. Advance Soil Science, v.16, p.213-234, 1991.

RAWLS, W. J. et al. Effect of soil carbon on soil water retention. Geoderma, v.116, p.61-76, 2003.

RESENDE, M. et al. Pedologia: base para distinção de ambientes. 5.ed. Lavras: Universidade Federal de Lavras, 2005. 338p.

RESENDE, M.; CARVALHO JR. A.; LANI, J. L. Características do solo e da paisagem que influenciam a susceptibilidade à erosão. In: SIMPÓSIO SOBRE MANEJO E CONSERVAÇÃO DO SOLO NO CERRADO, Goiânia. Anais... Campinas: Fundação Cargil, 1992. p.32-67.

ROMKENS, M. J. M.; HELMING, K.; PRASAD, S. $\mathrm{N}$. Soil erosion under different rainfall intensities, surface roughness, and soil water regimes.

Catena, v.46, p.103-123, 2001.

SANTOS, G. V. et al. Análise hidrológica e socioambiental da bacia hidrográfica do córrego Romão dos Reis, Viçosa-MG. Revista Árvore, v.31, n.5, p.931-940, 2007.

SANTOS, R. D. et al. Manual de descrição e coleta de solo no campo. 5.ed. Viçosa, MG: Sociedade Brasileira de Ciência do Solo, 2005. 92p.

SILVA, A. P.; KAY, B. D. Estimating the least limiting water range of soils from properties and management. Soil Science Society of America Journal, v.61, n.3, p.877-883, 1997.

SOTO, M. A. A.; KUMAYAMA, D. M.; CHANG, H. K. C. Calibração de um reflectômetro para estudos do fluxo de água em solo não saturado. Geociências, v.26, n.4, p.357-369, 2007.

Revista Árvore, Viçosa-MG, v.36, n.1, p.93-102, 2012 
van den BERG, M. et al. Pedotransfer functions for the estimation of moisture retention characteristics of Ferralsols and related soils. Geoderma, v.78, n.1, p.161-180, 1997.
ZARTL, A. S.; KLIK, A.; HUANG, C. Soil detachment and transport processes from interrill and rill areas. Physics and Chemistry of the Earth, v.26, n.1, p.25-26, 2001. 